J. Chem. Soc. Nigeria, Vol. 46, No.1, pp 0181 - 0190 [2021]

\title{
EXPLORATION OF INTERCALATED KAOLINITE CLAY FOR THE UPTAKE OF BASIC DYE BY ADSORPTION - EQUILIBRIUM, KINETICS AND THERMODYNAMIC STUDIES
}

\author{
C. E. Chigbundu ${ }^{1,2 *}$, K. O. Adebowale ${ }^{1}$ \\ ${ }^{1}$ Department of Chemistry, Faculty of Sciences, University of Ibadan, Oyo State, Nigeria. \\ ${ }^{2}$ Chemical and Food Sciences Department, Bells University of Technology, Ota, Ogun State, Nigeria. \\ *Corresponding author-. emmachijy@yahoo.com,+2348064541460 \\ Received 11 November 2020; accepted 22 November 2020, published online 30 January 2021
}

\begin{abstract}
Dyes are complex and sensitive organic chemicals which exposes microbial populations, aquatic lives and other living organisms to its toxic effects if their presence in water bodies or industrial effluents are not properly handled. This work therefore, comparatively studied the adsorption efficiencies of natural raw kaolinite (NRK) clay adsorbent and dimethyl sulphoxide (DMSO) faciley intercalated kaolinite clay (DIK) adsorbent for batch adsorption of Basis Red 2 (BR2) dye. The impact of varying the contact time, temperature and other operating variables on adsorption was also considered. The two adsorbents were characterized using SEM images, FTIR and XRD patterns. Linear and non-linear regression analysis of different isotherm and kinetic models were used to describe the appropriate fits to the experimental data. Error analysis equations were also used to measure the goodness-of-fit. Langmuir isotherm model best described the adsorption as being monolayer on homogenous surfaces while Kinetic studies showed that Elovich model provides the best fit to experimental data. The adsorption capacities of NRK and DIK adsorbents for the uptake of BR2 were $16.30 \mathrm{mg} / \mathrm{g}$ and $32.81 \mathrm{mg} / \mathrm{g}$, respectively (linear regression) and $19.30 \mathrm{mg} / \mathrm{g}$ and $30.81 \mathrm{mg} / \mathrm{g}$, respectively (non-linear regression). The thermodynamic parameter, $\Delta \mathrm{G}$ showed that BR2 dye adsorption onto the adsorbents were spontaneous. DIK adsorbent was twice efficient compared with NRK for the uptake of BR2 dye.
\end{abstract}

Keywords: Kaolinite; Adsorption; equilibrium; Basic Red 2; Intercalation; Thermodynamics

\section{INTRODUCTION}

Basic dyes are salts; they have positively charged chromogen. They are used in the industries to dye products or materials like paper and prints, polyacrylonitrile fibers, leather and plastics. Dyes are toxic and causes severe problems to both human and aquatic life [1,2]. Among which is the reduction of sunlight to aquatic flora necessary for photosynthesis, in the long run, it can lead to a decline in the population of the aquatic biota. In humans, dye toxicity could cause cancer, allergy, dermatitis, dysfunction of kidneys, liver and reproductive systems [2]. Increase in demand for basic dyes of competitive qualities by consumer has led to the synthesis of dyes with the ability to resist $\mathrm{pH}$, fading under sunlight or harsh weather conditions and non-degradation with time. These has made most conventional techniques of wastewater treatments such as the biological methods, chemical methods or even physical methods namely; sedimentation, membrane filtration, photo-catalysis to be either ineffective or very expensive to operate [2]. Consequently, researchers have explored and discovered adsorption technique. Adsorption technique is economical such that large investment costs are reduced. Various cheap adsorbents have been discovered some of which are agricultural wastes namely; rice straw, garlic peel, mango peel, orange waste, watermelon shell, eucalyptus seeds, [2]. Inorganic materials such as clays namely; kaolinite, and modified clays [3].

Clays are layered inorganic matter that has the ability to uptake other substances (either organic or inorganic) onto its surfaces or into their interlamellar spaces. However, to further improve on its adsorption capacity, surface modification have been studied such as organo-modification of bentonite clay with cetyltrimethylammonium bromide [4], kaolinite and bentonite with hexadecyltrimethylammonium bromide (HDTMA) and phenyl trimethylammonium bromide (PTMA). One other method of obtaining organo-modified clay is the interlayer space adaptation by the process of intercalation which involves the insertion of small polar organic molecules into the interlamellar space of the clay [5].

Kaolinite is a $1: 1$ phyllosilicate layered clay. It has high chemical and appreciable structural stability. Besides, it is found in large quantity in Nigeria [6]. This work, therefore, attempts to modify raw kaolinite clay by intercalation using standard methods to insert Dimethyl sulfoxide (DMSO) into 
the interlayer of the clay and study its efficiency in the uptake of Basic Red 2 (BR2) dye (aka Saffranin$\mathrm{O})$ as a model for cationic dyes removal from aqueous solution.

\section{MATERIALS AND METHODS}

\section{Adsorbate and Adsorbent}

The kaolinite clay materials used as adsorbent in this work was collected from one of the states of the South-South geo-political zone of Nigeria, namely: Delta state. Basic Red 2 (BR2) (Fig. 1, $\mathrm{C}_{20} \mathrm{H}_{19} \mathrm{ClN}_{4}$ ) was used as adsorbate. The molar mass of BR2 molecule is $350.85 \mathrm{~g} \cdot \mathrm{mol}^{-1}$ ( $80 \%$ dye content).<smiles>Cc1cc2nc3cc(C)c(N)cc3[n+](-c3ccccc3Cl)c2cc1N</smiles>

Fig 1. Chemical structure of Basic Red 2 (BR2).

Purification of natural raw kaolinite (NRK)

Heavier and settleable non clay substances were separated from the colloidal kaolinite clay suspension by decantation and the clay matter was recovered by centrifugation. The recovered natural kaolinite clay (NRK) was further purified with $30 \%$ hydrogen peroxide solution to allow complete oxidation of any carbonaceous matter present in it [7]. After, the supernatant was separated by centrifugation and the kaolinite washed thoroughly until it was peroxide free. The peroxide-free NRK clay was oven dried at $353 \mathrm{~K}$.

Preparation of dimethyl sulfoxide intercalated kaolinite (DIK)

$20 \mathrm{~g}$ of dried NRK was dispersed in $100.0 \mathrm{ml}$ of 25 $\%$ methanol $(\mathrm{v} / \mathrm{v})$ in a $500.0 \mathrm{ml}$ flat bottom flask fitted with a reflux condenser and heated on a hot plate with magnetic stirrer at $323 \mathrm{~K}$ for $3 \mathrm{~h}$ after which $200.0 \mathrm{ml}$ Dimethyl Sulphoxide (DMSO) solution was slowly added. The temperature of the set up was increased to $343 \mathrm{~K}$ and allowed to heat 10 $\mathrm{h}$ daily intermittently for 10 days. Afterwards, the sample was washed with hot ethyl alcohol to get rid of unused DMSO and methanol [7,8]. The washed sample was dried and gently crushed, labeled as DMSO-intercalated kaolinite (DIK) and stored.

\section{Adsorbent characterization}

NRK and DIK adsorbents were characterized using Fourier Transform Infrared (FTIR) spectra graph obtained using a SHIMADZU/FTIR spectrometer. Pro-X Phenom model Scanning Electron
Microscope (SEM) couple with Energy Dispersive $\mathrm{X}$-ray Spectrometer (EDX) for the morphological characterization of the adsorbents and X-Ray Diffraction (XRD) powder pattern of NRK and DIK was secured using a Philips PW 3064/60 diffractometer.

\section{ADSORPTION EXPERIMENT \\ Preliminary experiments}

Preliminary study of the batch adsorption was carried out using $800 \mathrm{mg}$ NRK and DIK adsorbents dispersed in $300 \mathrm{ml}$ dye solution of $100 \mathrm{mg} / \mathrm{L}$ concentration to determine the minimum time it will take to establish the adsorption equilibrium. The established time of $2 \mathrm{~h}$ was then used for the batch adsorption experiment. The point of zero charges (PZC) of the adsorbents were also determined

Secondly, calibration graph establishes linear correlation of the plot of dye concentration against absorbance $\left(\mathrm{R}^{2}=0.994\right)$. The absorbance characteristics of BR2 dye was $\lambda_{\max }=520 \mathrm{~nm}$ using UV-vis spectrophotometer [Surgifriend SM7504UV/visible 911]. The adsorption capacity of the dye was calculated using the following expression:

$$
\begin{aligned}
& Q e=\frac{\left(C_{o}-C_{e}\right) V}{m} \\
& \%=\frac{\left(C_{o}-C_{e}\right) \times 100}{C_{o}}
\end{aligned}
$$

Where Qe is quantity adsorbed $(\mathrm{mg} / \mathrm{g})$, $\mathrm{Co}$ and $\mathrm{Ce}$ are dye concentration at initial and at equilibrium $(\mathrm{mg} / \mathrm{L}), \mathrm{V}$ is the volume $(\mathrm{L})$ and $\mathrm{m}$ is the mass $(\mathrm{g})$.

Various operating conditions such as adsorbent dose, initial dye concentration, temperature and contact time were investigated using the methods described in Adebowale et al. [2].

\section{ADSORPTION ISOTHERM MODELS}

\section{Langmuir isotherm model}

This isotherm model assumed that the coverage on an adsorbate is monolayer and adsorption can only occur at the same energy on localized adsorption sites. Hence, forces of interaction between sorbed molecules are negligible [2]. The nonlinear expression of this isotherm is given as;

$$
q_{e}=\frac{q_{m} b C_{e}}{1+b C_{e}}
$$

While the linear form is expressed as; 
J. Chem. Soc. Nigeria, Vol. 46, No.1, pp 0181 - 0190 [2021]

$$
\frac{C_{e}}{q_{e}}=\frac{C_{e}}{q_{m}}+\frac{1}{b C_{e}}
$$

where qe, $\mathrm{Ce}, \mathrm{qm}$ and $\mathrm{b}$ represents the portion of solute adsorbed per unit mass of adsorbent at equilibrium $(\mathrm{mg} / \mathrm{g})$, the concentration of the solute left in solution at equilibrium $(\mathrm{mg} / \mathrm{L})$, the maximum adsorption capacity of adsorbate at equilibrium $(\mathrm{mg} / \mathrm{g})$ and the Langmuir constant which is related to the free energy of adsorption $(\mathrm{L} / \mathrm{mg}$ ), respectively.

\section{Freundlich isotherm model}

This model empirically expresses the heterogeneity on the surface of an adsorbent. Under the assumption that adsorption sites of a given adsorbent has different energy and that the portion of adsorbate adsorbed on the adsorbent compared to the portion left in solution unadsorbed, is proportional exponentially [3,9]. The nonlinear form of the mathematical is expression as follows:

$q_{e}=K_{F} C_{e}^{1 / n}$

While the linear form is expressed as;

$$
\log \left(q_{e}\right)=\log \left(K_{F}\right)+\frac{1}{n} \log \left(C_{e}\right)
$$

where $\mathrm{K}_{\mathrm{F}}, \mathrm{Ce}$ and $\mathrm{n}$ represent the Freundlich constant $\left(\mathrm{mg} / \mathrm{g} \cdot(\mathrm{mg} / \mathrm{L})^{\mathrm{n}}\right)$, the concentration of adsorbate adsorbed $\left(\mathrm{L} \cdot \mathrm{g}^{-1}\right)$ and the heterogeneity (dimensionless) factor relating to the adsorption intensity, respectively.

\section{Temkin isotherm model}

This isotherm model assumed that in a situation where the adsorbent-adsorbate interaction does not occur directly, the energy of all the atoms of the adsorbate adsorbed would drop or reduce linearly with coverage and that the adsorption is characterized by a uniform distribution of the bonding energies, up to some maximum binding energy $[9,10]$. The nonlinear form of the equation is given as follows;

$q_{e}=\frac{R T}{b_{T}} \ln A_{T} C_{e}$

While the linear form is as follows;

$$
q_{e}=\frac{R T}{b_{T}} \ln A_{T}+\left(\frac{R T}{b_{T}}\right) \ln C_{e}
$$

where $\mathrm{A}_{T}, \mathrm{~b}_{T}$, and $\mathrm{T}$ represents the Temkin isotherm constant $(\mathrm{L} / \mathrm{g})$, the constant related to energy of adsorption $(\mathrm{J} / \mathrm{mol})$ and the absolute temperature $(\mathrm{K})$, respectively, while $\mathrm{R}$ is the gas constant $(8.314$ $\mathrm{J} / \mathrm{mol} \mathrm{K}$ ).

\section{ADSORPTION KINETIC MODEL}

Several kinetic models are available to understand the mechanism and strength of sorbate retention on the adsorbent surface with time. In this study, the adsorption data were analyzed using four different kinetic models, namely the pseudo-first-order, pseudo-second order, Elovich and DiffusionChemisorption by means of nonlinear regression curves. The equations for each model are shown in table 1.

Table 1. Adsorption Kinetic equations fitted to investigate the adsorption of BR2 onto NRK and DIK

\begin{tabular}{ll}
\hline $\begin{array}{l}\text { Kinetic } \\
\text { Model }\end{array}$ & $\begin{array}{l}\text { Nonlinear } \\
\text { Equation }\end{array}$ \\
\hline Pseudo-first-order (PFOM) & $q_{t}=q_{e}\left(1-\exp \left(-K_{1} t\right)\right)$ \\
Pseudo-second-order (PSOM) & $q_{t}=\frac{k_{2} q_{e}^{2} t}{1+k_{2} q_{e} t}$ \\
Elovich & $q_{t}=\frac{1}{\alpha} \operatorname{Ln}(1+\alpha \beta t)$ \\
Diffusion-chemosorption (D-C) $q_{t}=\frac{1}{q e}+\frac{1}{K_{D C} * t^{0.5}}$
\end{tabular}

RESULT AND DISCUSSION Morphological characterization
The micrographs of both NRK and DIK adsorbents surface morphologies as well as their SEM/EDX are shown in Fig. 2. 
For NRK adsorbent, grainy homogenous particles with no form of aggregation were observable (Fig Uniformly dispersed smaller particles that seem coarser were noticeable which are likely to be the presence of silt and sandy component of the clay. Similar observation has also been reported $[13,15,16]$. The SEM/EDX of NRK indicated that the average atomic composition in percentages are; $\mathrm{O}$ (66.8\%), Si (17.6\%), $\mathrm{Al}(14.1 \%)$ and $\mathrm{C}(1.3 \%)$.

For DIK adsorbent, it was apparently a form of morphological evolution from NRK micrograph (Fig. 2b). This is possibly due to the adsorbents interlamellar space expansion by the insertion of DMSO molecule and also not overlooking the 2a). Also shown were Micro pits, micro voids and arrays of white patches.

effects of many factors involved in organo-clay surface modification such as heat, impact of agitator, the presence of modifier and others. In addition, there appeared on the DIK micrograph more of particle cohesion than that observed on NRK (Fig 2). The EDX analysis of DIK Adsorbent indicated that the average atomic composition in percentages are; O (71.2\%), Si (11.6\%), Al (9.9\%) and C (5.4\%). The obvious increase in percentage of oxygen and in addition, the presence of carbon is an indication of the presence of DMSO (Fig. 2).

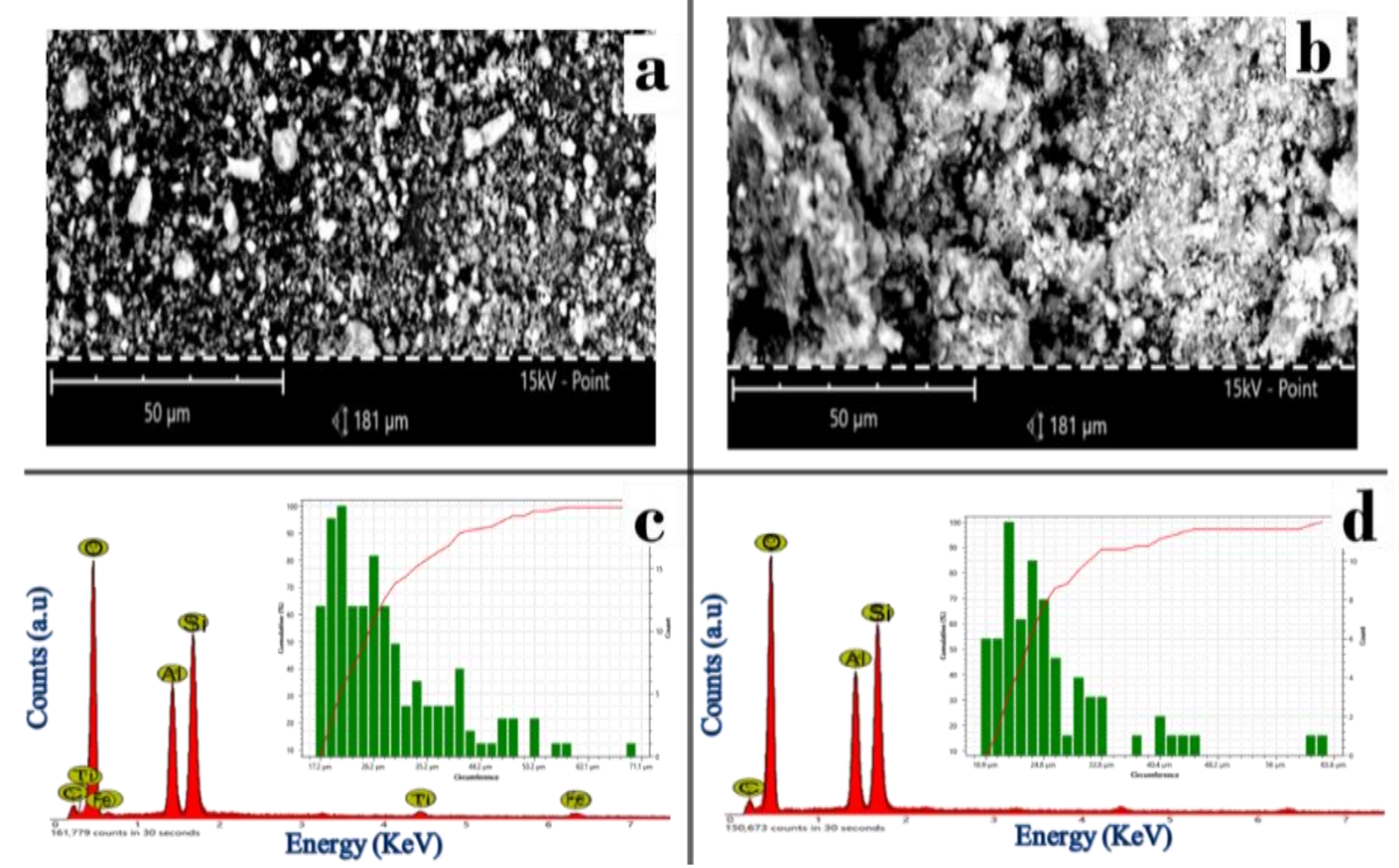

Fig. 2: SEM images of (a) NRK and (b) DIK, and EDX with particle size properties of (c) NRK and (d) DIK.

Infrared absorption spectra characterization

The Fourier transformed infrared spectra graph of NRK and DIK adsorbent are shown Fig 3. FTIR bands ascription was done by relating the result obtained in the literatures $[13,14,15]$. The inner-hydroxyl stretching band of the interlayer gallery of kaolinite is not by and large affected by the interlayer modification [7,8]. Hence, 3696, 3669 and $3652 \mathrm{~cm}^{-1}$ was ascribed to the inner hydroxyl bands of NRK while the band at $3620 \mathrm{~cm}^{-1}$ was ascribed to stretching frequency of internal $\mathrm{OH}^{-}$(Fig. $3)$. The broad band observed at around $3400 \mathrm{~cm}^{-1}$ was ascribed to $\mathrm{H}_{2} \mathrm{O}$ molecule in the interstice. The band at $536 \mathrm{~cm}^{-1}$ is due to the presence of $\mathrm{Si}-\mathrm{O}-\mathrm{Al}$ group. The bands at 1099 and $1006 \mathrm{~cm}^{-1}$ correspond

to $\mathrm{Si}-\mathrm{O}-\mathrm{Si}$ group. The band at $694 \mathrm{~cm}^{-1}$ is due to the bending mode of the same group $[13,16]$.

DIK spectra when compared with that of the NRK, showed a band at $3427 \mathrm{~cm}^{-1}$ assigned to O$\mathrm{H}_{\text {str }}$ of sulphoxide attached to the thio group of DMSO [7]. The multiple peaks was observed between 2840 and $2940 \mathrm{~cm}^{-1}$ (magnified) are attributed to carbon-hydrogen stretching vibration of 
methylene $\left(-\mathrm{CH}_{2}\right)$ and methyl $\left(-\mathrm{CH}_{3}\right)$ groups of DMSO (Fig. 3). In addition, the bands for the $\mathrm{OH}-$ groups were conspicuously observed around $1600-$ $1700 \mathrm{~cm}^{-1}$.

These peaks appeared as a result of inner surface $\mathrm{OH}$ and internal $\mathrm{OH}$ groups of NRK been perturbed by DMSO molecules [13,16,17]. Other additional obvious bands on DIK spectra, was an indication that the intercalation of functional organic molecules into the interlayer of the NRK clay material was successful.

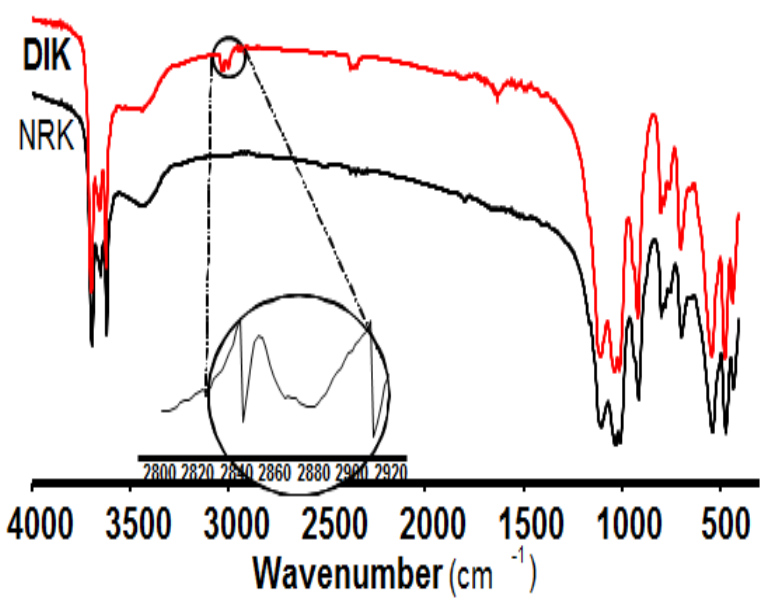

Fig 3. FTIR spectra of (a) DIK and (b) NRK adsorbent samples

XRD patterns for adsorbents characterization The identification of the kaolin mineral compositing components is done by comparing the peak intensity position $2 \theta\left(^{0}\right)$ in the sample X-ray diffraction pattern with the peak position value of the diffraction intensity $2 \theta\left(^{0}\right)$ standards contained in the Joint Committee for Powder Diffraction Standards (JCPDS).

The graph of X-Ray diffraction pattern for the absorption intensity peaks of NRK as shown in Fig. 4 appear at $2 \theta\left(^{0}\right) \approx 12.35^{0}, 19.79^{0}, 20.84^{0}$, $22.96^{0}, 24.81^{0}, 26.57^{0}, 34.94^{0}$.

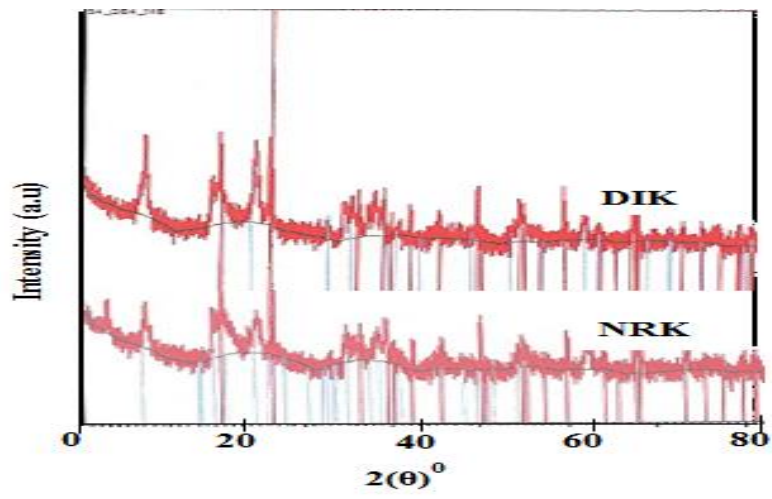

Fig 4. XRD patterns for DIK and NRK adsorbents.

But when the XRD (d001) reflection of NRK was compared with that of DIK after been intercalated with DMSO, the peak is observed to have shifted from $7.16\left(2 \theta\left(^{0}\right) \approx 12.35\right)$ to $11.2 \AA\left(2 \theta\left(^{0}\right) \approx 7.89\right)$ equivalent to $\Delta \mathrm{d}=4.04 \AA$ (Table 3 ).

Table 3: X-ray diffraction (XRD) analysis

\begin{tabular}{lccc}
\hline Samples & $\mathbf{2 \theta}^{\mathbf{0}}$ & $\mathbf{d}_{\mathbf{0 0 1}}(\AA)$ & $\boldsymbol{\Delta d}(\AA)$ \\
\hline NRK & 12.351 & 7.16 & - \\
DIK & 7.896 & 11.20 & 4.04 \\
\hline
\end{tabular}

\section{Point of zero charge}

$\mathrm{pH}$ point of zero charge (pHpzc)of NRK and DIK adsorbents was determined. The values were known by determining the point where the resulting curve cut through the $\mathrm{pH}$ axis as shown in Fig 5. The pHpzc was found to be 5.85 and 3.9 for NRK and DIK, respectively. The influence of all the functional groups present on each sorbent determines the net surface charge on each sample which is zero at the pHpzc. This then implied that (1) at $\mathrm{pH}<\mathrm{pHpzc}$, the sorbent surface has a net positive charge and the adsorption of Anions becomes more enhance at lower $\mathrm{pH}$ than the pHpzc. (2) at $\mathrm{pH}>\mathrm{pHpzc}$, the sorbent surface has net negative charges and the adsorption of cations are more enhanced at $\mathrm{pH}$ higher than pHpzc [19]. These are electrostatic interaction. However, other interaction such as chemical reaction may be stronger than purely electrstatic forces, making the effect of surface charge less importanton [20]. 


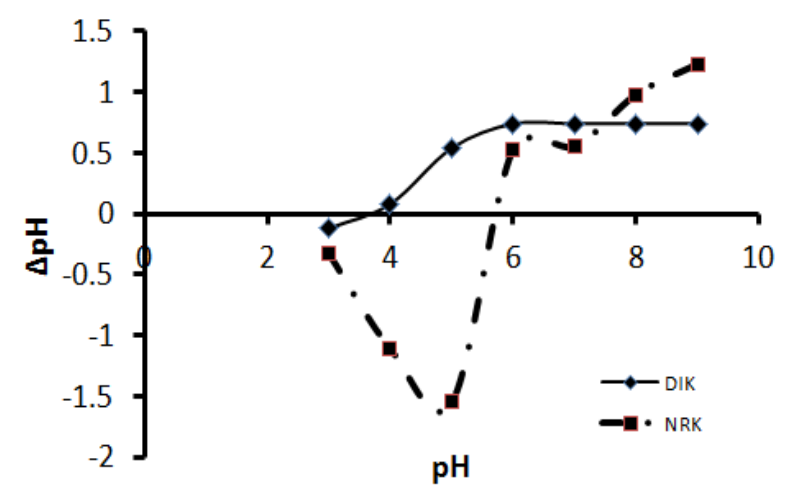

On the other hand, it was observed (Fig.5) that the adsorption of BR2 onto DIK was very fast within the same $\mathrm{pH}$ range of study such that across all the $\mathrm{pH}$ range the percentage dye removal was almost the same at approximately 87.32 to around $97.85 \%$. The interaction between DIK and BR2 dye therefore is either by complex formation or by chemical reaction which is stronger than purely electrostatic interaction as could be explained using pHpzc. A negatively charged (hydroxyl $(\mathrm{OH}-)$ and carbonyl groups $(\mathrm{CO})$ ) site on DIK reacts with cations on BR2 leading to the formation bonds by chemisorption

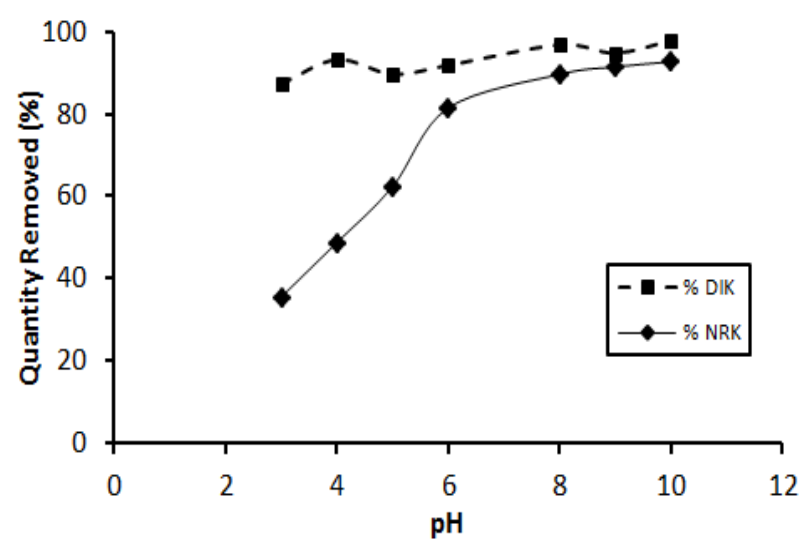

Fig. 5. Effect of $\mathrm{pH}$ on adsorption of BR2 dye by NRK and DIK.

\section{Effect of adsorbent dose variation}

There was a concomitant increase in adsorption sites consequent to increase in adsorbent dosage of NRK and DIK in the presence of constant BR2 dye concentration in solution as shown in Fig. 6. Hence, the percentage dye removal obviously increased steadily as the adsorbent dosage increases (Fig. 6) [2,9,10].
Fig 5 pHpzc of NRK and DIK adsorbents

\section{Effect of $\mathrm{pH}$ variation}

The study of the effect of $\mathrm{pH}$ showed that the quantity of dye removed by NRK increased as the $\mathrm{pH}$ increases in the alkaline region and also at $\mathrm{pH}>\mathrm{pHpzc}$. The percentage of BR2 dye removed was found to increase from $35.45 \%$ to about 92.73 $\%$ at about $\mathrm{pH}=10$ (Fig. 5) confirming an electrostatic interaction between NRK and BR2 dye.

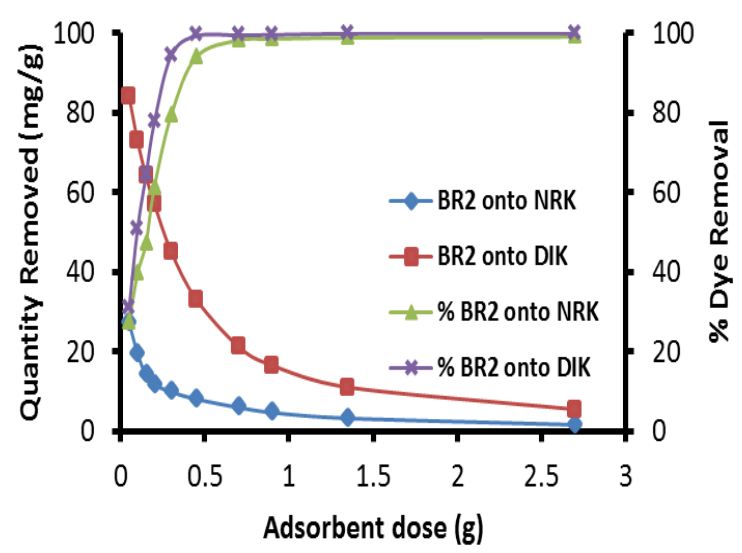

Fig. 6. NRK and DIK adsorbent dose variation

\section{Adsorption equilibrium}

The relation between the sorbate and sorbents at equilibrium during adsorption was studied using Langmuir, Freundlich and Tempkin adsorption isotherm model equations. The models were fitted to the experimental data by linear (not shown) and nonlinear regression plots (Fig. 7). In order to decide the best fit adsorption isotherm model equation, the coefficient of determination $\left(\mathrm{R}^{2}\right)$, and least values of Chi-square test $\left(\chi^{2}\right)$ were used to evaluate the experimental data (Table 4).

Langmuir isotherm with respect to the other isotherm models satisfactorily generated best fit to the experimental data for both linear and nonlinear analysis for the dye adsorption onto NRK and DIK. The highest $R^{2}$ values for NRK and DIK are 0.9987 and 0.9968 respectively for linear and 0.9300 and 0.9841 respectively for nonlinear regressions. Although Langmuir isotherm does not explain the mechanism of the adsorption reaction, yet it assumed that the interaction 
J. Chem. Soc. Nigeria, Vol. 46, No.1, pp 0181 - 0190 [2021]

Table 4 Adsorption Isotherm for BR2 dye uptake comparing linear and nonlinear regression

\begin{tabular}{|c|c|c|c|c|c|}
\hline \multirow[b]{2}{*}{ Isotherm } & \multirow[b]{2}{*}{ Parameter } & \multicolumn{2}{|c|}{ Linear Regression } & \multicolumn{2}{|c|}{ Non-Linear Regression } \\
\hline & & $\overline{\mathrm{NRK}}$ & $\overline{\mathrm{DIK}}$ & $\overline{\mathrm{NRK}}$ & DIK \\
\hline \multirow[t]{4}{*}{ Langmuir } & $\mathrm{q}_{\max }(\mathrm{mg} / \mathrm{g})$ & 16.39 & 32.26 & 19.30 & 30.81 \\
\hline & $\mathrm{K}_{\mathrm{L}}(\mathrm{L} / \mathrm{g})$ & 0.427 & 0.120 & 0.160 & 1.530 \\
\hline & $\mathrm{R}^{2}$ & 0.9987 & 0.9968 & 0.9300 & 0.9841 \\
\hline & $\chi^{2}$ & 4.360 & 2.990 & 3.650 & 0.980 \\
\hline \multirow[t]{4}{*}{ Freundlich } & $\mathrm{K}_{\mathrm{F}}(\mathrm{L} / \mathrm{g})$ & 6.315 & 6.315 & 4.540 & 18.77 \\
\hline & $\mathrm{n}$ & 0.249 & 0.341 & 2.7 & 6.770 \\
\hline & $\mathrm{R}^{2}$ & 0.6271 & 0.7334 & 0.8523 & 0.7163 \\
\hline & $\chi^{2}$ & 58.98 & 21.71 & $5.22 \times 10^{51}$ & $8.87 \times 10^{29}$ \\
\hline \multirow[t]{4}{*}{ Temkin } & $\mathrm{A}_{\mathrm{T}}(\mathrm{L} / \mathrm{g})$ & 2.624 & 5.769 & 3.370 & 4.020 \\
\hline & $\mathrm{K}_{\mathrm{T}}(\mathrm{KJ} / \mathrm{mol})$ & 9.754 & 1.665 & 2.890 & 84.21 \\
\hline & $\mathrm{R}^{2}$ & 0.7197 & 0.8257 & 0.8644 & 0.8186 \\
\hline & $\chi^{2}$ & 5.250 & 19.52 & 8.260 & 8.130 \\
\hline
\end{tabular}

between the adsorbent and the adsorbate is by chemical bonding (chemisorption) within the homogeneous site on the adsorbent $[10,13,18]$. Evidently as shown in table 4, the adsorption capacity of DIK is about twice that of NRK adsorbent for the uptake of BR2 dye from aqueous solution with the values of 16.39 and $32.26 \mathrm{mg} / \mathrm{g}$ for linear regression respectively while it is 19.30 and $30.81 \mathrm{mg} / \mathrm{g}$ for nonliniear respectively.

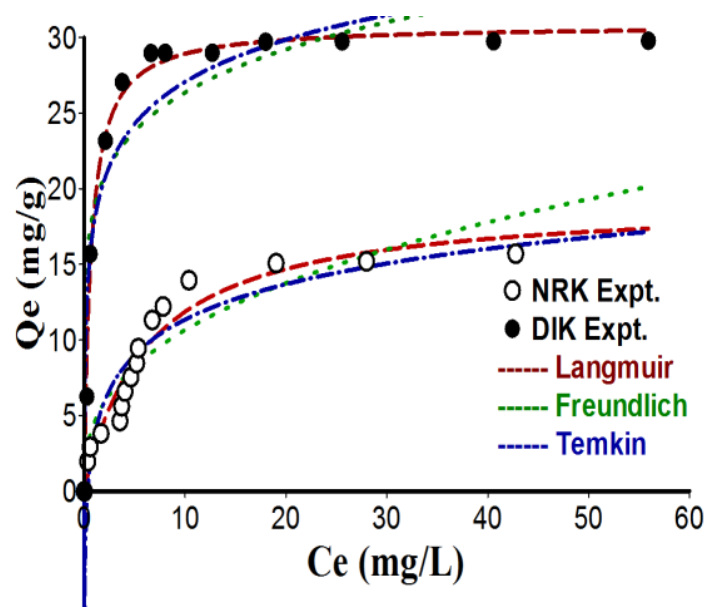

Fig. 7. Non-linear isotherm model regression curves for the adsorption of BR2 onto DIK and NRK

\section{Contact time and adsorption kinetic consideration}

The influence of contact time on the adsorption of BR2 dye onto NRK and DIK adsorbents at different adsorbent dose (1.5 g and $2.5 \mathrm{~g})$ was studied at an allowed contact time of $120 \mathrm{~min}$ for a sufficient adsorbate-adsorbent interaction in solution.
As was shown (Fig. 8 and 9), in the initial stage of the curve, the rate of adsorption was rapid within or less than the first $10 \mathrm{~min}$ of BR2 uptake while at above $10 \mathrm{~min}$ another stage sets in that was gradual in rising, showing a decrease in the rate of adsorption until the attainment of equilibrium. This implied that, in the initial stage, a large number of vacant adsorption sites were freely available, so a fast adsorption occurred, whereas in the following stage, a slow BR2 adsorption was attributed to the decreased availability of active adsorption sites and a long period of time for diffusion of the adsorbate molecules into the pores or interlayer of the absorbents [21].

Evaluating the adsorption kinetics of BR2 onto DIK and NRK, four different kinetic model equations were used to fit the experimental data, namely; pseudo-first order, pseudo-second order, Elovich and diffusion chemisorption kinetic models as shown in Table 5. Three different statistical error functions were also used to corroborate the best fitted model decided by the coefficient of determination $\left(\mathrm{R}^{2}\right)$ (Table 6). As shown in Table 5 , the coefficient of determination $\left(\mathrm{R}^{2}\right)$ of the Elovich model was highest which was supported by the least values of the error functions in Table 6. Therefore, Elovich model satisfactorily described the adsorption of BR2 onto NRK and DIK adsorbents. Hence it can be explained that reaction mechanism is via chemisorption partly due to interaction between the positively charged BR2 dye and the active sites on the surface of the adsorbents and partly also due to coulombic force of attraction [22] 
J. Chem. Soc. Nigeria, Vol. 46, No.1, pp 0181 - 0190 [2021]

Table 5 Kinetics parameter for different kinetic models for NRK and DIK adsorbents

\begin{tabular}{|c|c|c|c|c|c|c|c|c|c|c|c|c|c|}
\hline \multirow[b]{2}{*}{ Sorbent } & \multirow[b]{2}{*}{ Mass } & \multicolumn{3}{|c|}{ PFOM } & \multicolumn{2}{|c|}{ PSOM } & \multirow[b]{2}{*}{$\overline{\mathrm{R}^{2}}$} & \multicolumn{3}{|c|}{ Elovich } & \multicolumn{3}{|c|}{ Diff-Chemisorption } \\
\hline & & $\begin{array}{r}\mathrm{qe}_{\mathrm{cal}} \\
(\mathbf{m g} / \mathbf{g})\end{array}$ & $\begin{array}{l}\mathrm{k}_{1} \\
\left(\mathbf{m i n}^{-1}\right)\end{array}$ & $\mathrm{R}^{2}$ & $\begin{array}{l}\mathrm{qe}_{\mathrm{cal}} \\
(\mathbf{m g} / \mathbf{g})\end{array}$ & $\begin{array}{l}\mathrm{k}_{2} \\
\text { (g/mg.min) }\end{array}$ & & $\underset{\left(\mathrm{g} / \mathbf{m g}^{-} \mathbf{m i n}^{-1}\right)}{\alpha}$ & $\underset{(\mathrm{g} / \mathrm{mg})}{\beta}$ & $\mathrm{R}^{2}$ & $\begin{array}{l}\mathrm{qe}_{\mathrm{cal}} \\
(\mathrm{g} / \mathrm{mg} \cdot \mathrm{min}\end{array}$ & $\begin{array}{l}\mathrm{K}_{\mathrm{DC}} \\
\left.\text { (g/mg.min }{ }^{0.5}\right)\end{array}$ & $\mathrm{R}^{2}$ \\
\hline \multirow[t]{2}{*}{ NRK } & $1.5 \mathrm{~g}$ & 13.75 & 1.855 & 0.9933 & 13.91 & 0.246 & 0.9967 & 0.841 & $3.83 \times 10^{4}$ & 0.9982 & 47.65 & 13.91 & 0.9957 \\
\hline & $2.5 \mathrm{~g}$ & 16.51 & 2.755 & 0.5416 & 16.79 & 0.443 & 0.7799 & 0.744 & $3.15 \times 10^{8}$ & 0.8278 & 124.9 & 16.79 & 0.7789 \\
\hline \multirow[t]{2}{*}{ DIK } & $1.5 \mathrm{~g}$ & 25.86 & 3.048 & 0.9907 & 25.95 & 0.364 & 0.9916 & 1.103 & $3.30 \times 10^{8}$ & 0.9962 & 244.9 & 25.95 & 0.9948 \\
\hline & $1.5 \mathrm{~g}$ & 18.99 & 1.901 & 0.6797 & 19.37 & 0.197 & 0.8379 & 1.128 & $5.61 \times 10^{5}$ & 0.9907 & 73.98 & 19.37 & 0.8369 \\
\hline
\end{tabular}

Table 6 The goodness-of-fit at different adsorbent weights for predicting best fitted kinetic model.

\begin{tabular}{|c|c|c|c|c|c|c|c|c|c|}
\hline \multirow[b]{2}{*}{ Models } & \multirow[b]{2}{*}{ Mass } & \multirow[b]{2}{*}{$\mathrm{R}^{2}$} & \multicolumn{3}{|c|}{ NRK } & \multirow[b]{2}{*}{$\mathrm{R}^{2}$} & \multicolumn{3}{|c|}{ DIK } \\
\hline & & & SSQ & Variance & $\chi^{2}$ & & SSQ & Variance & $\chi^{2}$ \\
\hline \multirow[t]{2}{*}{$\overline{\mathrm{PFOM}}^{1 *}$} & 1.5 & 0.9933 & 1.188 & 0.132 & 0.198 & 0.9907 & 5.221 & 1.044 & 0.243 \\
\hline & 2.5 & 0.5416 & 5.471 & 0.456 & 0.332 & 0.6797 & 11.536 & 1.923 & 0.727 \\
\hline \multirow[t]{2}{*}{$\mathrm{PSOM}^{2 *}$} & 1.5 & 0.9967 & 0.583 & 0.065 & 0.144 & 0.9916 & 4.731 & 0.946 & 0.265 \\
\hline & 2.5 & 0.7799 & 2.628 & 0.219 & 0.158 & 0.8379 & 5.836 & 0.973 & 0.417 \\
\hline \multirow[t]{2}{*}{ Elovich } & 1.5 & 0.9982 & 0.824 & 0.103 & 0.122 & 0.9962 & 2.137 & 0.427 & 0.128 \\
\hline & 2.5 & 0.8278 & 2.056 & 0.171 & 0.130 & 0.9907 & 0.334 & 0.056 & 0.084 \\
\hline \multirow[t]{2}{*}{$D-C^{3 *}$} & 1.5 & 0.9948 & 0.583 & 0.065 & 0.144 & 0.9916 & 4.731 & 0.946 & 0.357 \\
\hline & 2.5 & 0.8369 & 2.628 & 0.219 & 0.158 & 0.8379 & 5.836 & 0.973 & 0.332 \\
\hline
\end{tabular}

$1 *$-(Pseudo First Order Model) $2 *$-(Pseudo Second Order Model)

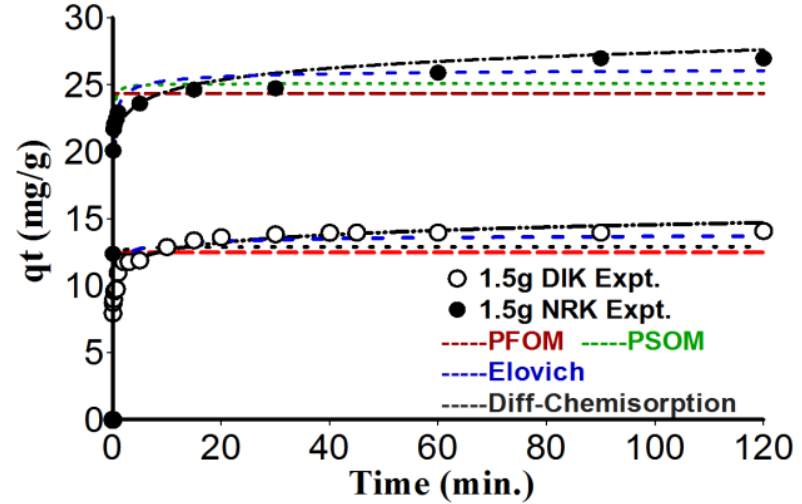

Fig 8. Adsorption kinetic curve of BR2 dye adsorption at $1.5 \mathrm{~g}$ adsorbent dosage.

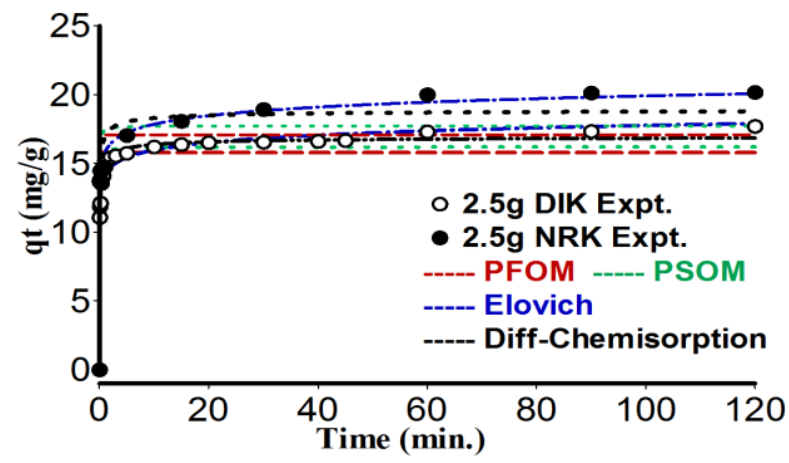

Fig 9. Adsorption kinetic curve of BR2 dye adsorption at $2.5 \mathrm{~g}$ adsorbent dosage.

\section{Adsorption thermodynamics}

Studying the effect of temperature, the values of the thermodynamic parameters of the adsorption process was evaluated using the following expressions:

$$
\begin{aligned}
\boldsymbol{k}_{d} & =\frac{\boldsymbol{C e}_{\boldsymbol{A}}}{\boldsymbol{C} \boldsymbol{e}_{s}} \\
\ln \left(k_{d}\right) & =\frac{\Delta S_{a d s}}{R}-\frac{\Delta H_{a d s}}{R T} \\
\Delta G_{a d s} & =\Delta H_{a d s}-T \Delta S_{a d s}
\end{aligned}
$$

Where $k_{d}$ is the distribution coefficient at different temperatures and it's equal to the ratio of the concentration of dye adsorbed $\left(\mathrm{Ce}_{\mathrm{A}}\right.$ in $\left.\mathrm{mg} / \mathrm{L}\right)$ to the concentration of dye unadsorbed at equilibrium $\left(\mathrm{Ce}_{\mathrm{S}}\right.$ in $\mathrm{mg} / \mathrm{L}$ ) at different temperatures and $\mathrm{R}$ is the gas constant. The values of $\Delta \mathrm{H}_{\mathrm{ads}}$ and $\Delta \mathrm{S}_{\mathrm{ads}}$ were obtained from the slope and intercept of the linear plot of $\operatorname{lnk}_{\mathrm{d}}$ versus $1 / T$, respectively. While the standard Gibb's free energies $\left(\Delta \mathrm{G}_{\mathrm{ads}}\right)$ was calculated accordingly by the use of equation 15

The values obtained for the standard free energy are negative (i.e. $\Delta \mathrm{G}_{\mathrm{ads}}<0$ ) as shown in Table 8 and this implied that the reaction at the solid-solution interface during the adsorption process was feasible 
and spontaneous. The spontaneity of adsorbate adsorbent interaction reaction between NRK and BR2 tends to decrease as the temperature of the system increases indicating that the process is by physisorption $[4,10]$. This is supported by the magnitude and sign of the enthalpy $\left(\Delta \mathrm{H}_{\mathrm{ads}}=-35.34\right)$, meaning that the adsorption process of BR2 dye onto NRK is exothermic nature (Table 8). Meanwhile, the interaction between DIK and BR2 dye showed an increase in spontaneity as the temperature was increased which pointes to the fact that the process was by chemisorption. The value obtained for the standard enthalpy change is positive $\left(\Delta \mathrm{H}_{\mathrm{ads}}=+31.06\right)$ meaning that the adsorption BR2 onto DIK is endothermic in nature involving the absorption of heat energy from outside the system. The negative entropy change $\left(\Delta \mathrm{S}_{\mathrm{ads}}\right)$ value for NRK interaction with BR2 (Table 8) corresponds to a decrease in the degree of freedom of the adsorbate while the positive value for DIK corresponds to increase in the degree of freedom of the adsorbed BR2 [2,4,10].

Table 8 Thermodynamic Parameters for BR2 adsorption onto NRK and DIK

\begin{tabular}{|c|c|c|c|c|c|c|}
\hline \multirow[b]{2}{*}{ Sorben } & \multicolumn{4}{|c|}{$\Delta \mathrm{G}(\mathrm{KJ} / \mathrm{mol})$} & \multirow[b]{2}{*}{$\Delta \mathrm{H}^{*}$} & \multirow[b]{2}{*}{$\Delta \mathrm{S}^{* *}$} \\
\hline & $293 \mathrm{~K}$ & $303 K$ & $313 \mathrm{~K}$ & $328 \mathrm{~K}$ & & \\
\hline NRK & -10.23 & -8.45 & -7.45 & -7.24 & -35.34 & -85.72 \\
\hline DIK & -6.69 & -7.60 & -8.91 & -11.16 & 31.06 & 128.2 \\
\hline
\end{tabular}

\section{CONCLUSION}

In this work, the interlayer space of NRK was successfully expanded using DMSO through the process of intercalation. NRK and DIK adsorbents were successfully used for the adsorption of BR2 dye from aqueous solution. The results showed that the adsorption of BR2 dye onto NRK and DIK was greatly influenced by increasing adsorption time, initial dye concentration and $\mathrm{pH}$. Moreover, the adsorption of BR2 dye occurred on a homogeneous surface by monomolecular layer coverage and was by chemical reaction. Furthermore, the two adsorbents (NRK and DIK) showed preference for the uptake of BR2 dye though DIK showed a higher dye adsorption capacity than NRK. According to Langmuir model, adsorption capacity of DIK is about $32.3 \mathrm{mg} / \mathrm{g}$ being twice that of NRK adsorbent at about $16.4 \mathrm{mg} / \mathrm{g}$. The kinetic study revealed that Elovich model satisfactorily fit the experimental data and consequently, the mechanism of adsorbate-adsorbent interaction was by chemisorption. The study of the effect of temperature showed that the adsorption of BR2 onto NRK was exothermic while the adsorption of BR2 onto DIK was endothermic. However, the interaction of both adsorbents with BR2 was spontaneous.

Acknowledgements: This was made possible by the permission of University of Ibadan, Ibadan, Oyo State and Bells University of Technology, Ota, Ogun State, Nigeria to use their research laboratories. We are grateful.

Conflict of interest: The authors hereby declare that they have no conflict of interest.

\section{References.}

[1] R. Hazzaa and M. Hussien (2015), Proceedings of the 14th International Conference on Environmental Science and Technology Rhodes, Greece, Pp. 3-5.

[2] K. O. Adebowale, B. I. Olu-Owolabi, E. C. Chigbundu (2014), Removal of Saffranin-O from Aqueous Solution by Adsorption onto Kaolinite Clay. Journal of Encapsulation and Adsorption Sciences. $\quad 4$, 89-104. http://dx.doi.org/10.4236/jeas.2014.43010

[3] W. N. Martens, R. L. Frost, J. Krist and E. Horvath (2002), Modification of Kaolinite Surfaces through Intercalation with Deuterated Dimethyl sulfoxide. Journal of Physical Chemistry B. $106 \quad$ (16), 4162-4171. doi:10.1021/jp0130113.

[4] H. B. Senturk, D. Ozdes, A. Gundogdu, C. Duran and M. Soylak (2009), Removal of phenol from aqueous solutions by adsorption onto organomodified Tirebolu bentonite: equilibrium, kinetic and thermodynamic study. Journal of Hazardous Materials, 172 (1), 353-62.

[5] U.F. Alkaram, A.A. Mukhlis, and A. H. Al-Dujaili (2009), The removal of phenol from aqueous solutions by adsorption using surfactantmodified bentonite and kaolinite. Journal of Hazardous Materials, 169 (1-3), 324-32.

[6] A. A. Aliyu, B. A. Aluko and K. O. Biliaminu (1996), Priority investment projects in the solid minerals sector. Raw materials Research and Development Council, Abuja. Pp 12-14.

[7] S. Zhang, Q. Liu, H. Cheng and F. Zeng (2015), Combined experimental and theoretical investigation of interactions between kaolinite inner surface and intercalated dimethyl sulfoxide. Applied Surface Science. 331, 234240 https://doi.org/10.1016/j.apsusc.2015.01.019 
J. Chem. Soc. Nigeria, Vol. 46, No.1, pp 0181 - 0190 [2021]

[8] W. Tang, L. Song, S. Zhang, H. Li, J. Sun and X. $\mathrm{Gu}$ (2017), Preparation of thiourea-intercalated kaolinite and its influence on thermostability and flammability of polypropylene composite. Journal of Materials Science. 52, 208-217. https://doi.org/10.1007/s10853016-0323-8

[9] A. Syafiuddin, S. Salmiati, J. Jonbi and M. A. Fulazzaky (2018), Application of the kinetic and isotherm models for better understanding of the behaviors of silver nanoparticles adsorption onto different adsorbents. Journal of Environmental Management. 218, 59-70. https://doi.org/10.1016/j.jenvman.2018.03.066

[10] T. P. K. Murthy, B. S. Gowrishankar, M. N. C. Prabha, M. Kruthi and R. H. Krishna (2019), Studies on batch adsorptive removal of malachite green from synthetic wastewater using acid treated coffee husk: Equilibrium, kinetics and thermodynamic studies. Microchemical Journal. 146, 192-201.

https://doi.org/10.1016/j.microc.2018.12.067

[11] N. Rahman and M. Nasir (2020), Effective removal of acetaminophen from aqueous solution using $\mathrm{Ca}$ (II)-doped chitosan $/ \beta$ cyclodextrin composite. Journal of Molecular Liquids. 301, 112454.

https://doi.org/10.1016/j.molliq.2020.112454

[12] C. Sutherland and C. Venkobachar (2010), A Diffusion-Chemisorption Kinetic Model for Simulating biosorption Using Forest MacroFungus, Fomes fasciatus. International Research Journal of Plant Scienc. 1(4), 107-117.

[13] A. Mbaye, C. A. K. Diop, J. Miehe-Brendle, F. Senocq and F. Maury (2014), Characterization of natural and chemically modified kaolinite from Mako (Senegal) to remove lead from aqueous solutions. Clay Minerals. 49 (4), 527-539. ISSN 0009-8558:

doi.org/10.1180/claymin.2014.049.4.03

[14] M. Belhadri, A. Mokhtar, S. Meziani, F. Belkhadem, M. Sassi and A. Bengueddach (2019), Novel low-cost adsorbent based on economically modified bentonite for lead(II) removal from aqueous solutions. Arabian Journal of Geosciences. 12, 234 -256.

[15] Y. Guo, C. Tan, J. Sun, W. Li, J. Zhang and C. Zhao (2020), Porous activated carbons derived from waste sugarcane bagasse for $\mathrm{CO}_{2}$ adsorption. Chemical Engineering Journal. 381, 122736.

[16] D. Wang, Q. Liu, D. Hou, S. Zhang, P. Guo and H. Cheng (2018), Improved Method for Preparation of Methoxy-Modified Kaolinite. Journal of the Brazilian Chemical Society. 29, 1 - $\quad 22 . \quad$ http://dx.doi.org/10.21577/0103$\underline{5053.20170109}$

[17] D.A. Adekeye, S.S. Asaolu, S.O. Adefemi, A.A. Adebawore, O.S. Osundare, O.A. Ibigbami and A.H. Olumide (2019), Clay Soil Modification Techniques for the Adsorption of Heavy Metals in Aqueous Medium: A Review. International Journal of Advanced Research in Chemical Science (IJARCS) 6 (6) 14-31. DOI: http://dx.doi.org/10.20431/2349-0403.0606003

[18] M.A.K. M. Hanafiah, S.C. Ibrahim and M. Z. A. Yahya, (2006), Equilibrium Adsorption Study of Lead Ions onto Sodium Hydroxide Modified Lalang (Imperatacylindrica) Leaf Powder. Journal of Applied Sciences Research. 2 (12), 1169-1174.

[19] F. O. Nwosu, O. J. Ajala, R. M. Owoyemi and B. G. Raheem (2018), Preparation and characterization of adsorbents derived from bentonite and kaolin clays. Applied Water Science. $\quad 8 \quad$ (195), $1-10$ https://doi.org/10.1007/s13201-018-0827-2

[20] E. N. Bakatula, D. Richard, C. M. Neculita and G. J. Zagury (2018), Determination of point of zero charge of natural organic materials Environmental Science and Pollution Research https://doi.org/10.1007/s11356-017-1115-7

[21] H. Wei, J. Sun, B. Zhang and R. Liu (2020) Comparative Study of Cationic Dye Adsorption Using Industrial Latex Sludge with Sulfonate and Pyrolysis Treatment. Sustainability. $\quad 12 \quad$ (23) 10048 ; https://doi.org/10.3390/su122310048 www.arcjournals.org

[22] Y. Kuang, X. Zhang and S. Zhou (2020), Adsorption of Methylene Blue in Water onto Activated Carbon by Surfactant Modification. Water. 12 (587), 1 -19. doi:10.3390/w12020587. 